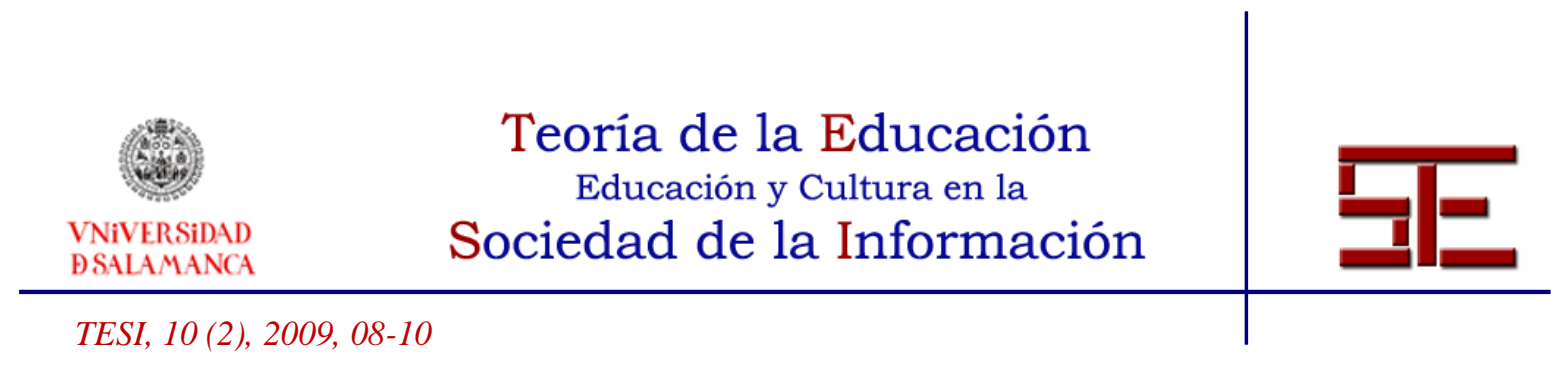

\title{
EDITORIAL: "CONSTRUYENDO LA SOCIEDAD DIGITAL. UN DESAFÍO PARA LAS CIENCIAS SOCIALES"
}

\author{
Carlos Ferrás Sexto \\ carlos.ferras@usc.es \\ Universidad de Santiago de Compostela.
}

Los discursos relativos a las relaciones entre cultura, territorio y economía, surgen en los años noventa por parte de los sociólogos con preocupaciones tecnológicas. Manuel Castells observa como el concepto de cultura adquiere nuevas dimensiones en la Sociedad de la Información. Considera que Internet es por sí misma una creación cultural que genera nuevas formas de relación social, así como nuevas actividades productivas relacionadas con la difusión de contenidos culturales, incidiendo sobre todos los ámbitos de vida de los individuos y colectividades. Distingue cuatro capas culturales que interactúan con Internet y pueden definir prácticas innovadoras y creativas: la Cultura Universitaria, como institución que promueve la cultura de la investigación por la investigación, es decir, la generación de nuevos conocimientos básicos para el progreso científico; la Cultura Hacker que se identifica con la pasión por innovar y crear de forma desinteresada a través de Internet; la Cultura Alternativa, de gente insatisfecha que encuentra en Internet nuevas formas de expresión y estilos de vida distintos a los imperantes; y, por último, la Cultura Empresarial que denota una falta de aversión al riesgo y una gran capacidad de innovación. Sin embargo a todas ella podemos añadir una quinta capa denominada Cultura Territorial que a través de la identificación cultural de una comunidad con el espacio vital en el que vive y se desarrolla está en condiciones de promover sus intereses y comunicarse a través de la red. Todas estas capas culturales son la semilla de profundos cambios en la nueva Sociedad de la Información; la interacción de las mismas puede provocar nueva posibilidades creativas e innovadoras, dando lugar a nichos de empleo o nuevos productos culturales objeto de consumo y comercialización a través del uso de las Nuevas Tecnologías de la Información, pero también a la promoción del territorio concreto para mostrarse como espacio atractivo para vivir, visitar o recibir inversiones.

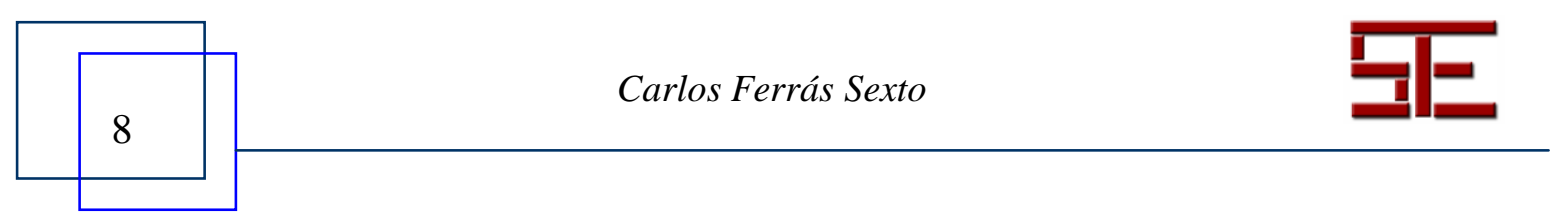




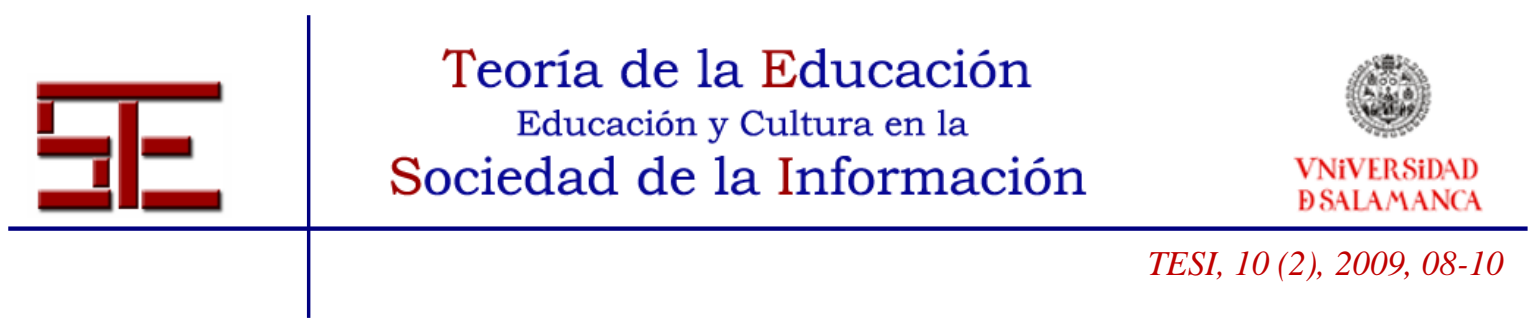

Es decir la cultura tangible e intangible se muestra estrechamente relacionada con el proceso de desarrollo económico que puede experimentar cualquier comunidad y/o territorio.

Internet, como producto cultural, procede originalmente de un proyecto de defensa (Arpanet) del Pentágono norteamericano. Fue empleada para la investigación en universidades y laboratorios, pero la difusión social de Internet correspondió a los agentes económicos que descubrieron en la "red de redes" grandes posibilidades de hacer negocios, comercializando con la producción de información y conocimiento. Hoy tenemos en Internet ofertas de servicios e información muy diversos: las bibliotecas, los museos, los servidores de música, las bases de datos socio-económicas, la cartografía digital, la literatura y la información periodística, etc., que se conciben como productos que se venden y compran ofertados por nuevas empresas. Además, la primera fuente de financiamiento de los websites es la publicidad. En la actualidad, el anuncio más caro del planeta no está en la portada de los principales periódicos nacionales o internacionales, ni en los espacios publicitarios de las grandes cadenas de televisión, sino en los "banners" que encabezan las páginas web más visitadas de Internet. En este contexto, frente a la proliferación de las páginas web concebidas como negocio, son frecuentes las páginas culturales concebidas como instrumentos de difusión de ideas políticas, o bien aquellas que suelen emplearse como instrumentos para buscar el apoyo político o económico de algún particular, organización o institución concreta.

En este contexto, debemos reflexionar sobre el hecho de que las TIC en los espacios rurales y periféricos enganchados, es decir con la tecnología accesible, permiten revalorizar y difundir las culturas locales y las identidades comunitarias. La música, las tradiciones, los estilos de vida y la cultura popular en general pueden convertirse en productos digitales ofertados en el mercado global a través del comercio electrónico en Internet. Además, la difusión masiva de la cultura local permite y contribuye enormemente a reforzar la identidad cultural y a frenar la emigración tradicional en territorios periféricos o de naturaleza rural que conocen la informarginación. La difusión de la cultura local a través de Internet puede contribuir a aumentar la calidad de vida de las comunidades locales y regionales apartadas de las grandes urbes y de los espacios más desarrollados y urbanizados del planeta. Podemos percibir que la economía cultural en interacción con las nuevas tecnologías puede facilitar la comunicación y puede transformar los territorios urbanos y/o rurales de la periferia preservando su existencia cultural, pues facilitan su conexión e interacción con otros espacios superarando su aislamiento. Además, en el mundo globalizado está adquiriendo gran relevancia la

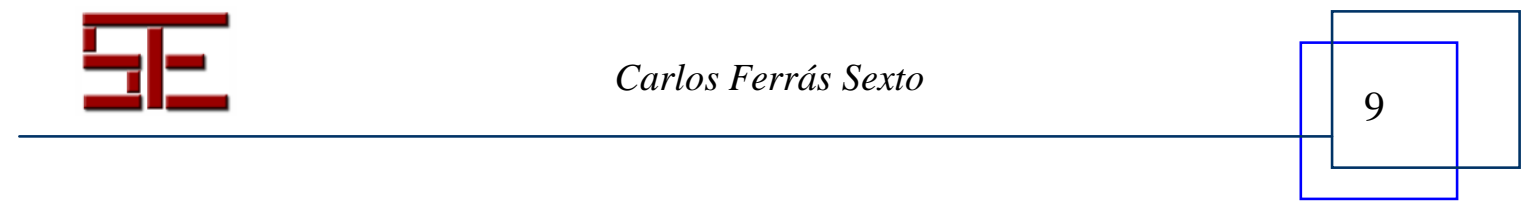




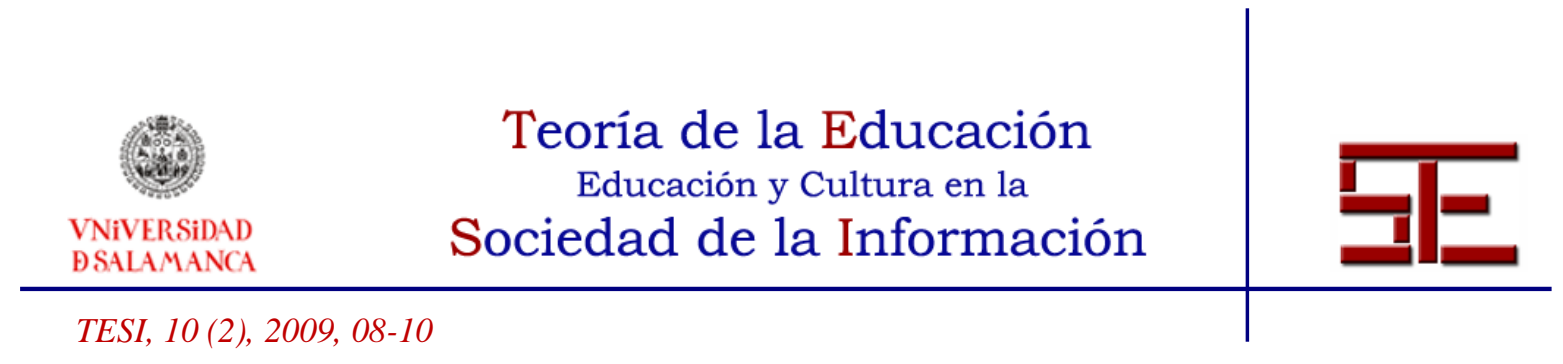

imagen de conjunto que ofrece una ciudad, municipio, región, país o territorio en general. Su imagen y sus características marcan su capacidad para ofrecer y atraer recursos económicos y servicios tecnológicos, financieros o culturales procedentes de ciudadanos, turistas, políticos e inversores.

En este contexto la Revista de Teoría de la Educación muestra un compendio de artículos seleccionados en ámbitos internacionales relativos a la investigación de las Tecnologías de la Información y a sus impactos en la sociedad, en la cultura y en la economía. A partir de la observación participante desde el enfoque etnográfico, y en proyectos consolidados irlandeses como es el caso de Northside Folk Project de la University College Cork, la "digitalización de la cultura popular" irlandesa persigue el progreso social en barrios urbanos. Esto se complementa con la observación crítica que realiza Joao Sarmento acerca de las utilidades TIC en países en desarrollo como la India o Uganda donde las prioridades sociales todavía son primarias; o el énfasis en los impactos de las TIC en una sociedad cada vez más plural y conectada a Internet, que quedan reflejados en las nuevas redes sociales y formas de "hacer política" a través del análisis y estudio de caso en Galicia; o la necesidad de la superación de la brecha digital rural en Portugal a través de la implantación definitiva de las redes de conexión a Internet de Banda Ancha. Se complementa la visión empírica con la visión de orden teórico con una reflexión autorizada acerca del significado de la calidad de vida en la Sociedad de la Información y la presentación de una metodología para el manejo eficiente de los fondos de investigación y bases de datos científico-tecnológicos.

En definitiva, el lector se encontrará con ideas, propuestas, análisis críticos, descripciones, que son un auténtico desafío para la reflexión y valoración del significado que las TIC tienen o pueden llegar a tener en el presente y en el futuro inmediato de nuestras ciudades, aldeas, comunidades, empresas, partidos políticos, etc.

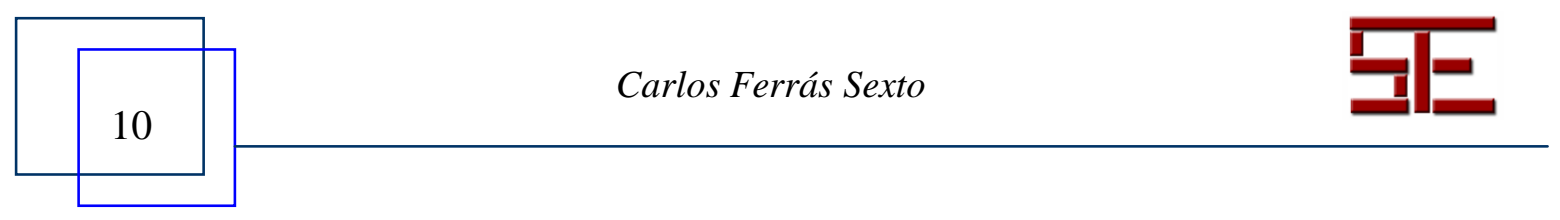

